\title{
ARTIGO
}

\section{ANÁLISE DE FALHAS EM EQUIPAMENTOS E A IMPORTÂNCIA DO PLANEJAMENTO DE MANUTENÇÃO: UMA APLICAÇÃO EM UMA USINA SUCROALCOOLEIRA ${ }^{1}$}

\author{
Felipe Campos Silva Barbosa ${ }^{2}$ \\ Paulo César de Resende Andrade
}

\begin{abstract}
RESUMO
Mediante os avanços tecnológicos, a globalização do mercado e a demanda por produção com menores custos, as organizações atuais visam a uma maior produtividade, requerendo equipamentos com alta confiabilidade e disponibilidade. Surge, então, a necessidade de maximizar o tempo em operação da planta industrial, de modo a garantir maior produção. $\mathrm{O}$ objetivo deste trabalho foi realizar uma análise de falhas de equipamentos utilizados no setor de moagem de cana-de-açúcar de uma usina sucroalcooleira. O método de pesquisa aplicado consistiu no estudo de caso. Para as análises, foi realizada a coleta de tempos até a falha dos equipamentos e, para a modelagem dos dados, utilizou-se o software ProConf. A modelagem da confiabilidade e da taxa de falhas dos equipamentos foi feita de modo a identificar a fase de vida destes. A distribuição que melhor se ajusta aos tempos é a Weibull. Foi possível gerar os gráficos da confiabilidade e da taxa de falhas, identificando que os equipamentos se encontram na fase de vida senil, sendo mais indicada a manutenção preventiva. Verificou-se que a folga excessiva entre os elementos rolantes que compõem o sistema do balanção era a principal causa de falhas no guincho Hillo, sendo então projetado um Anel-Guia para o cabo, de modo a evitar mais problemas.
\end{abstract}

Palavras-chave: Confiabilidade. Fase de vida. Manutenção preventiva. Modelagem. Weibull.

\section{INTRODUÇÃO}

A atual conjuntura econômica demanda produtos de qualidade, para suprir as necessidades e expectativas dos clientes, com custos competitivos. Assim, as organizações devem melhorar e agilizar cada vez mais seus processos para atenderem ao mercado e, ao mesmo tempo, avaliar os custos de sua produção. A expansão tecnológica, mesclada ao processo de globalização e redução das fronteiras, além de fatores como a responsabilidade socioambiental, indica a crescente evolução industrial (SOUZA, 2008).

\footnotetext{
${ }^{1}$ Como citar este artigo: BARBOSA, Felipe Campos Silva; ANDRADE, Paulo César de Resende. Análise de falhas em equipamentos e a importância do planejamento da manutenção: uma aplicação em uma usina sucroalcooleira. ForScience: revista científica do IFMG, Formiga, v. 7, n. 2, e00638, jul./dez. 2019. DOI: 10.29069/forscience.2019v7n2.e638.
}

${ }^{2}$ Autor para correspondência: Felipe Campos Silva Barbosa, E-mail: fcsb-lf@ hotmail.com. 
Surge, então, a necessidade uma integração ativa entre o processo produtivo e a manutenção, visando à excelência da planta industrial, maximizando a disponibilidade e a manutenabilidade dos equipamentos. A análise das falhas nos equipamentos ou instalações e as ações a serem tomadas para minimizar falhas na planta operacional refletem na confiabilidade e na disponibilidade da operação.

A confiabilidade está relacionada à operação bem-sucedida de um produto ou sistema, na ausência de quebras ou falhas. Já a disponibilidade é a capacidade de um item ou processo desempenhar suas funções durante um tempo determinado, mediante manutenção apropriada (FOGLIATTO; RIBEIRO, 2009).

Com a crescente competitividade industrial, a produção em massa e a maior qualidade dos produtos e serviços passaram a exigir mais de máquinas e equipamentos nas plantas industriais. Logo, a manutenção, antes vista como um desperdício, agora é reconhecida como uma função estratégica em meio aos processos (CARDOSO; PERES; NETO, 2011).

Segundo Waeyenbergh e Pintelon (2002), a manutenção desempenha um papel fundamental em nível de produção e logística nas organizações, gerando maior flexibilidade, qualidade, disponibilidade e, também, maior competitividade empresarial.

Para Kardec e Nascif (2009), a manutenção não deve ser empregada apenas para reparar um equipamento ou instalação em menor tempo. Deve ser planejada para manter o equipamento disponível para o processo, evitando falhas e reduzindo o risco de paradas inesperadas e não planejadas. Os autores consideram crucial a definição correta de missão da manutenção, seus conceitos básicos e seus paradigmas, assim como a aplicação destes fatores às organizações. Com o bom emprego destas ferramentas, é possível aumentar a competitividade da empresa.

Ainda há empresas que encaram o planejamento da manutenção como uma ferramenta dispensável e sem importância, tratando-a como uma simples atividade de reparo. Entretanto, Fuentes (2006) ressalta que a manutenção tem importante papel na logística da organização e deve ser uma ferramenta efetiva para alcançar a excelência empresarial e, consequentemente, alta competitividade e bons resultados.

Dados da Associação Brasileira de Manutenção (ABRAMAN), em uma pesquisa feita no ano de 2013, revelam que as empresas brasileiras estão investindo mais na área de manutenção (ABRAMAN, 2013). Para consolidar o planejamento e o controle eficaz da manutenção no meio operacional, é imprescindível o conhecimento dos modelos aplicáveis. Logo, os gestores de manutenção devem ter ampla visão e atuação em suas organizações. Ter uma árvore de equipamentos cadastrados contendo planos de manutenção e lubrificação, a 
quantidade adequada de peças sobressalentes e mão de obra especializada são fatores fundamentais para a maximização da disponibilidade de equipamentos, bem como dos lucros da empresa.

Em meio à competitividade industrial entre as organizações e diante da importância da manutenção no meio operacional, este trabalho visa mostrar a aplicabilidade do planejamento e do controle da manutenção em equipamentos que compõem o setor de moagem de cana-deaçúcar em uma indústria sucroalcooleira.

Para isso, foi necessário realizar uma análise das falhas dos equipamentos mecânicos que compõem o setor de moagem de cana-de-açúcar; efetuar um comparativo anual de falhas nos equipamentos; fazer a análise de confiabilidade e disponibilidade dos ativos; e, levantar e indicar melhores modelos a serem empregados no processo produtivo, com base nos métodos de manutenção.

Portanto, este trabalho se justifica na necessidade de se conhecer os conceitos importantes relativos à aplicação efetiva da manutenção junto aos processos de produção nas empresas. O conhecimento sobre os ativos e os processos, bem como acerca dos fatores que causam maiores impactos nas falhas ou quebras destes equipamentos, é de suma importância para o planejamento da manutenção. Por isso, este estudo visa integrar a análise de falhas de alguns equipamentos ao planejamento da sua manutenção e às opções dos modelos desta a serem aplicados.

Além disso, o cenário do planejamento e controle da manutenção, no Brasil, é ainda pouco difundido. Conforme Cardoso, Peres e Neto (2011), muitas empresas não possuem um controle efetivo da manutenção, concentrando suas ações apenas em manutenções corretivas, sem o conhecimento dos fatores que possam estar causando falhas, ou de melhores modelos que possam ser aplicados aos processos.

\section{REFERENCIAL TEÓRICO}

\subsection{O setor sucroalcooleiro no Brasil}

O Brasil é o maior produtor mundial de cana-de-açúcar, concebendo grande importância para o agronegócio brasileiro. Em meio a condições climáticas favoráveis ao cultivo da cana-de-açúcar, crescente demanda mundial por combustíveis oriundos de fontes renováveis e grandes áreas cultiváveis, o Brasil se mostra um país promissor para a exportação dessa commodity (CONAB, 2018). 
Mediante uma maior preocupação socioambiental das pessoas e empresas, a agroindústria sucroalcooleira se mostra com crescimento favorável. Ao longo dos anos, devido ao crescimento da tecnologia Fuel-flex nos automóveis leves, a produção de biocombustíveis vem se intensificando. Resultado disso é maior produção de etanol, que tem capacidade para substituir o uso da gasolina, e que, portanto, tem grande mercado consumidor.

Além da produção de etanol e açúcar, as unidades sucroalcooleiras têm visado a uma maior eficiência com a geração de energia elétrica pela queima de biomassa oriunda dos processos de produção, auxiliando, desse modo, na redução de custos e na sustentabilidade da atividade (CONAB, 2018). Para isso, é necessário que os equipamentos utilizados nos processos tenham a máxima confiabilidade e desempenho possíveis.

\subsection{Funcionamento de uma Usina Sucroalcooleira}

Uma planta sucroalcooleira é geralmente dividida em setores: Pesagem; Recepção de Cana; Preparação de Cana; Extração de Caldo; Tratamento de Caldo; Geração de Vapor e Energia; Fabricação de Açúcar e Fabricação de Álcool. Estes setores têm em comum a canade-açúcar, ou seus derivados, como matéria-prima. Na Figura 1, está exemplificado o fluxograma em uma planta industrial, apresentando os produtos e subprodutos de cada etapa. 


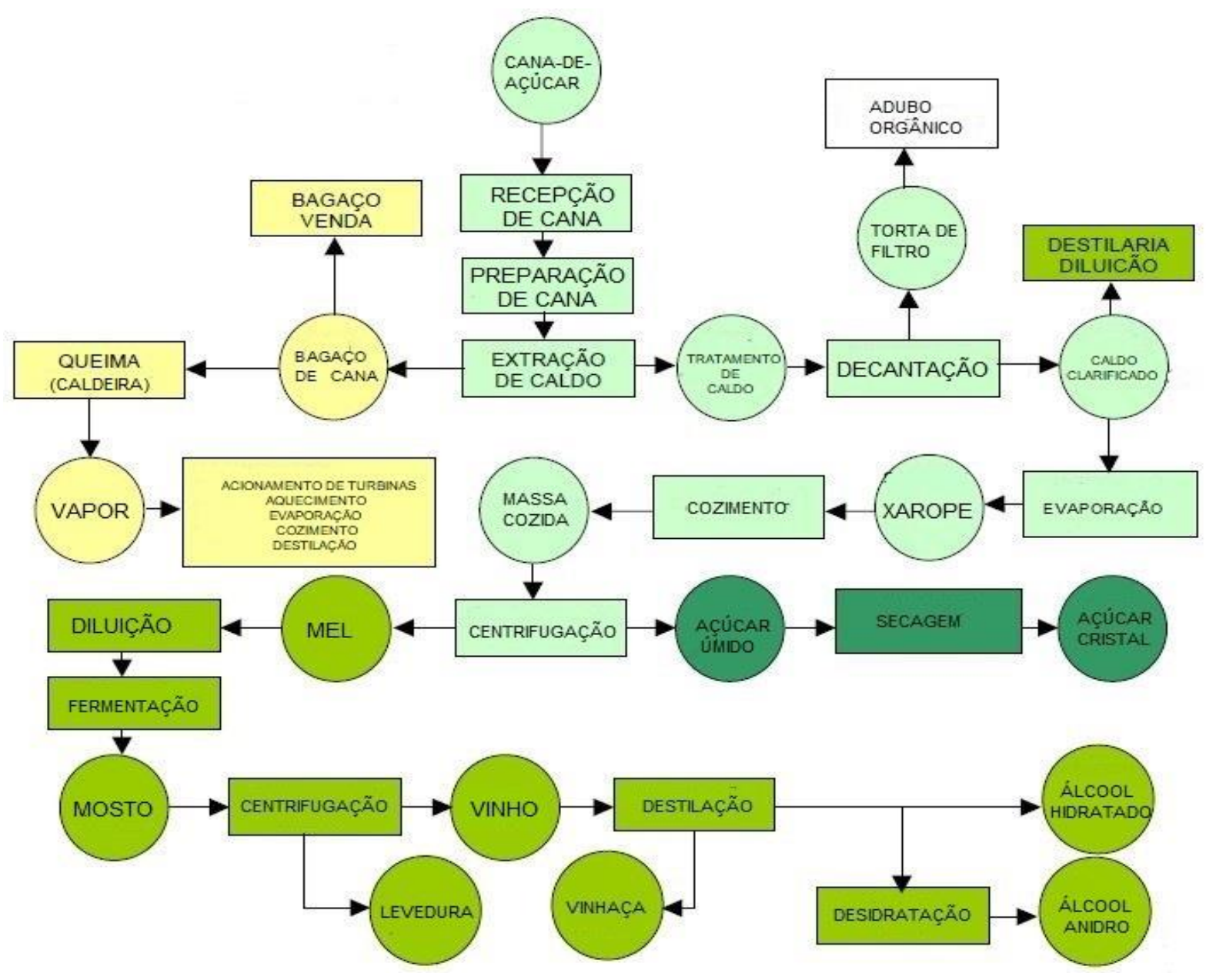

Figura 1 - Fluxograma da Cana de Açúcar numa Planta Industrial Sucroalcooleira Adaptado de: Cirino et al. (2018).

A colheita da cana-de-açúcar é feita por máquinas ou manualmente e, o transporte é realizado por caminhões até a indústria. Ao chegar à usina, o caminhão carregado é pesado. Após a pesagem, a cana é descarregada na mesa alimentadora por um equipamento denominado guincho Hillo. Conforme Leal (2014), a necessidade de descarregar os caminhões rapidamente foi motivo crucial para o desenvolvimento e a ampla utilização do guincho Hillo nas usinas. A mesa alimentadora é usualmente construída com uma inclinação de 35 a $45^{\circ}$ com a horizontal. A recepção de cana é composta pela mesa alimentadora e o guincho Hillo, que podem ser visualizados na Figura 2. 


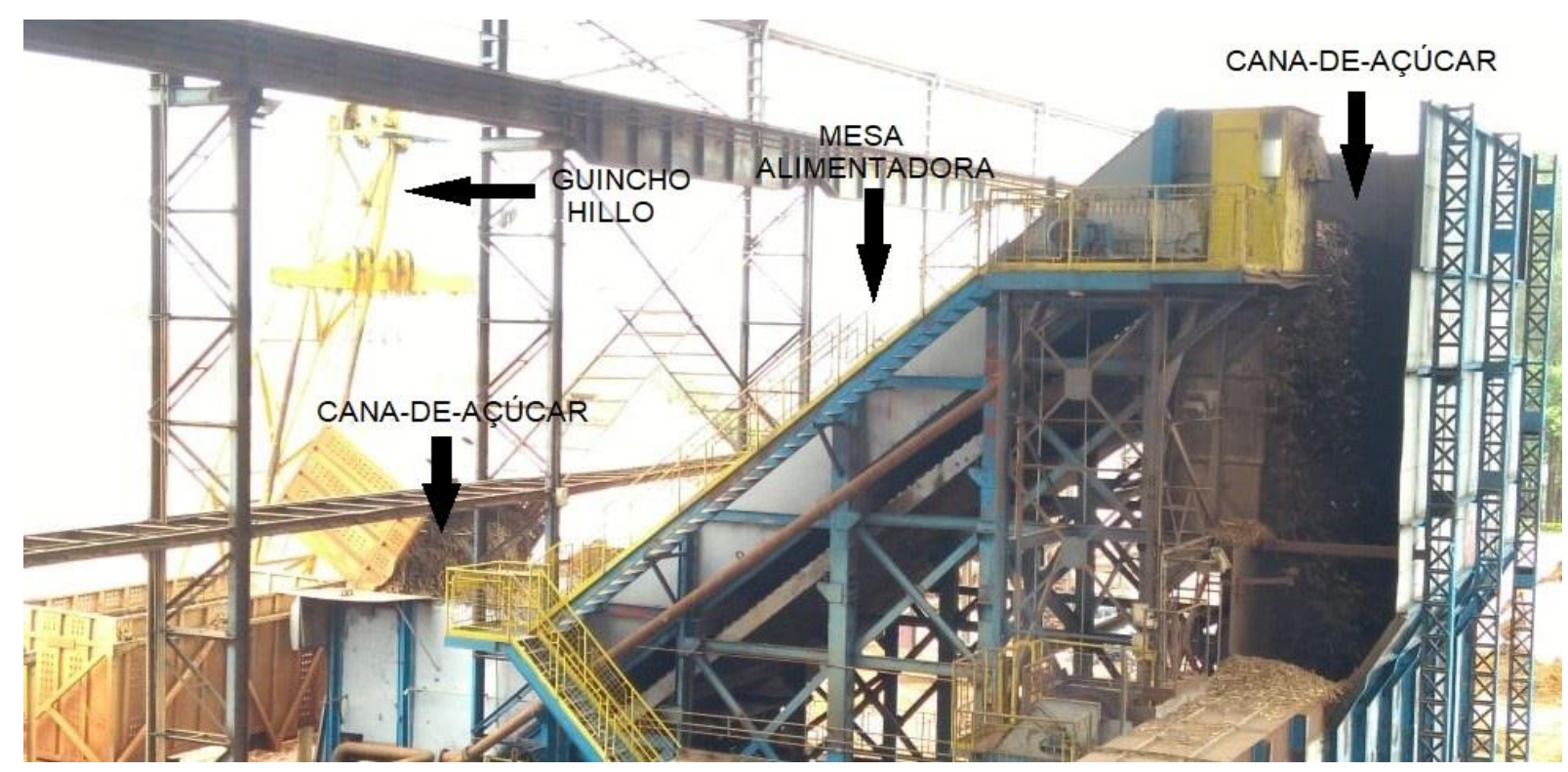

Figura 2 - Guincho Hillo e Mesa Alimentadora

Fonte: Elaborado pelo autor e autorizado pela empresa.

Seguindo para a preparação, a cana-de-açúcar é conduzida por uma esteira metálica, passando pelo desfibrador. Segundo Leal (2014), devido à cadeia de equipamentos pesados e interconectados por esteiras e correias transportadoras, o desempenho geral das moendas, e consequentemente, de toda a indústria depende de uma sequência de operações bem projetadas e otimizadas.

A moagem é um dos mais importantes setores da planta operacional, pois, a partir dela, inicia-se toda a cadeia produtiva sucroalcooleira. Requer altos investimentos, altos custos de operação e manutenção e causa impacto direto na eficiência global da indústria (LEAL, 2014). Logo, este setor requer maior integração entre operação e o planejamento e controle da manutenção, a fim de se obter maior disponibilidade e confiabilidade.

\subsection{Manutenção}

A Associação Brasileira de Normas Técnicas (ABNT), em 1994, por meio da NBR 5462 (ABNT, 1994), define manutenção como a combinação de todas as ações técnicas e administrativas, incluindo as de supervisão, destinadas a manter ou recolocar um item em um estado no qual possa desempenhar uma função requerida.

Segundo Kardec e Nascif (2009, p.23), a manutenção tem como objetivo "garantir a confiabilidade e a disponibilidade da função dos equipamentos e instalações de modo a 
atender a um processo de produção ou de serviço, com segurança, preservação do meio ambiente e custos adequados".

Conforme explica Waeyenbergh e Pintelon (2002), a implementação do conceito de manutenção é crucial para a definição das diretrizes de manutenção e o desenvolvimento integrado aos processos. Deste modo, a manutenção tem grande influência em todas as atividades desenvolvidas na organização.

A manutenção pode ser dividida em quatro gerações, segundo Kardec e Nascif (2009). Na primeira geração, antes da Primeira Guerra Mundial, a manutenção não era sistematizada, sendo empregada apenas como limpeza, lubrificação ou reparo após quebra. Ou seja, era puramente corretiva e não planejada.

A segunda geração começa após a Segunda Guerra, entre os anos 1950 e 1970, evidenciando a necessidade de maior disponibilidade e confiabilidade dos ativos, almejando maior produtividade. De acordo com Moubray (1997), isto fomentou a ideia de que as falhas dos equipamentos deveriam ser evitadas ou antecipadas por meio de revisões com periodicidade determinada, resultando no conceito de manutenção preventiva.

Em meados da década de 1970, tem-se o início da terceira geração, quando se aceleraram os processos de mudança nas plantas industriais, evidenciados com o crescimento da automação e mecanização. Com isso, a confiabilidade e a disponibilidade se tornaram cruciais nos mais diversos setores, uma vez que paralisações dos processos culminavam em menor capacidade de produção e, consecutivamente, em perdas e aumento de custos (KARDEC; NASCIF, 2009; MOUBRAY, 1997). Nesta geração, reforçaram-se o conceito e a utilização da manutenção preditiva, bem como a aplicação do conceito de confiabilidade e a inserção da Manutenção Centrada na Confiabilidade (MCC).

A quarta geração abrange os tempos atuais. A manutenção tem como desafio a minimização de falhas dos equipamentos e maior disponibilidade, confiabilidade e manutenibilidade dos ativos. Procurando intervir o mínimo possível nas plantas operacionais e nos ativos, as práticas da manutenção preditiva e o monitoramento das condições dos equipamentos e processos têm sido cada vez mais utilizados. Com isso, reduz-se a utilização da manutenção preventiva, enquanto a corretiva não planejada torna-se um indicador de ineficiência da manutenção (KARDEC; NASCIF, 2009).

A Engenharia de Manutenção engloba as práticas de todos os modelos já citados, utilizando dados coletados para análise, estudos e proposição de melhorias contínuas às plantas operacionais. Tem como objetivo consolidar a rotina e implementar melhorias, a fim 
de aumentar a confiabilidade, a disponibilidade e a manutenabilidade, eliminando problemas crônicos e solucionando problemas tecnológicos (KARDEC; NASCIF, 2009).

A implementação da Engenharia de Manutenção tem como pertinências as análises de falhas e a aplicação de ferramentas da manutenção para isso. As consequências das falhas devem sempre ser levadas em consideração na definição dos planos de manutenção numa planta operacional. Portanto, o estudo das consequências das falhas é de suma importância para a inserção da Manutenção Centrada na Confiabilidade, bem como a escolha das funções significantes de uma instalação (KARDEC; NASCIF, 2009).

A Manutenção Centrada na Confiabilidade (Reliability Centered Maintenance - RCM) é uma ferramenta que consiste num processo de estudo visando às diversas formas de como um componente ou sistema pode vir a falhar e, através disso, culminar nas ações de manutenção necessárias. É um importante instrumento para a tomada de decisões gerenciais, mediante as diretrizes de manutenção a serem seguidas no processo industrial (VIANA, 2002).

\subsection{Análise de Confiabilidade}

A confiabilidade de um equipamento pode ser descrita em termos de sua probabilidade em desempenhar a função até um tempo de interesse. A determinação deste indicador é obtida através da modelagem dos tempos até a falha do item em estudo. Conhecendo-se o modelo de distribuição que melhor se ajusta a esses tempos, é possível conhecer o equipamento e os indicadores a respeito deste (FOGLIATTO; RIBEIRO, 2009). As funções mais utilizadas em estudos de confiabilidade são as funções de confiabilidade $R(t)$ e de falha ou de risco $h(t)$.

São utilizadas, geralmente, quatro distribuições de probabilidade para descrever tempos até a falha de equipamentos e componentes: Exponencial, Gama, Lognormal e Weibull (FOGLIATTO; RIBEIRO, 2009). A modelagem dos tempos até as falhas é essencial para a análise de confiabilidade, sendo que vários estudos foram realizados recentemente (SANTOS et al., 2017; SILVA et al., 2017; BRANDÃO; ANDRADE, 2018; LEAL; ANDRADE, 2018; SILVA; ANDRADE, 2018).

Ao longo do ciclo de vida do equipamento, a curva da banheira (Figura 3) sintetiza a função de risco, expressando a expectativa de falha de um item ao longo do tempo (SELLITTO, 2005). 


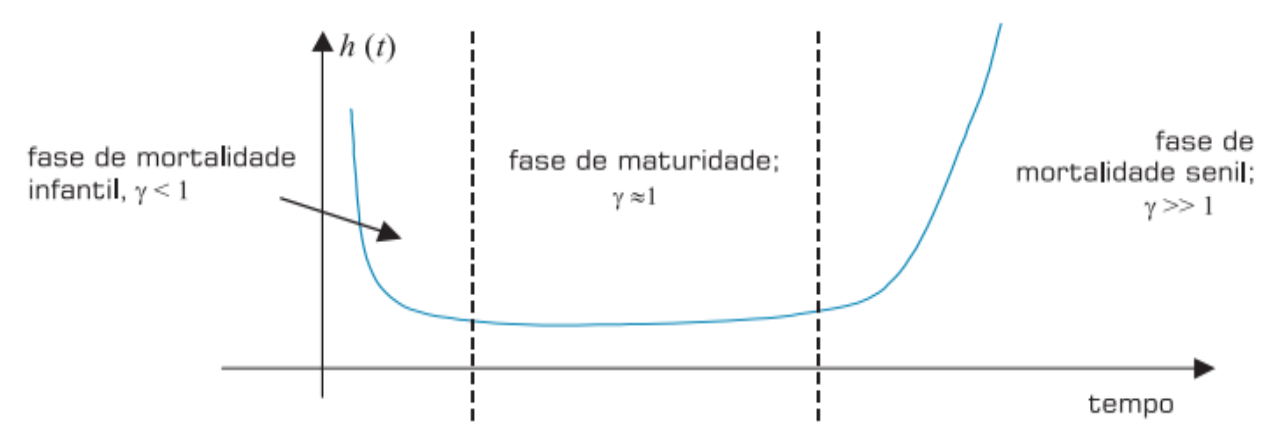

Figura 3 - Curva da Banheira

Fonte: Sellitto ( 2005).

De acordo com Sellitto (2005), o modelo de distribuição Weibull delineia várias situações de equipamentos que apresentam funções de risco distintas. $\mathrm{O}$ autor relaciona cada fase da curva a um comportamento da função de risco $h(t)$, pelo parâmetro de forma $\gamma$ da distribuição de Weibull, e também associa a cada fase da curva uma estratégia de manutenção mais adequada. Quando $\gamma<1, h(t)$ é decrescente, retrata a fase de mortalidade infantil do equipamento, caracterizada por defeitos na sua instalação ou manutenção, ou, ainda, defeitos de fabricação ou de projeto, sendo indicada a manutenção corretiva. Quando $\gamma=1$, pode-se assumir que o equipamento se encontra na fase de maturidade, onde a ocorrência de falhas é puramente aleatória, originadas por operação incorreta ou cargas excessivas. Nesta fase, é indicada a manutenção preditiva, acompanhando a operação. Por fim, quando $\gamma>1$, a taxa de falhas é crescente, caracterizando o período de mortalidade senil do item. Este estágio ocorre devido ao desgaste natural das partes com o tempo e a operação, sendo a manutenção preventiva empregada neste caso. O parâmetro de escala $\theta$ nfluencia tanto a média quanto a dispersão dos tempos de falha de um equipamento.

\section{MATERIAL E MÉTODOS}

No presente trabalho, foram analisadas as falhas de equipamentos mecânicos que compõem o setor de moagem de cana-de-açúcar em uma usina sucroalcooleira, composto por vários equipamentos e sistemas que, em conjunto, processam toda a cana que chega à planta operacional. No caso de falha em qualquer um destes equipamentos, a operação é parada durante o tempo de reparo, uma vez que eles seguem uma linha de produção em série.

Atualmente, os componentes de alguns sistemas dos equipamentos no setor são dotados de dispositivos de automação e monitoração; entretanto, ainda assim ocorrem falhas 
inesperadas. Os dados de falha foram disponibilizados pela empresa para a realização do estudo, e o conjunto de dados fornecidos apresenta a data e a hora das falhas e o tempo de reparo referente às safras de 2017/2018 e 2018/2019. A partir da obtenção dos equipamentos que apresentaram maior tempo de reparo, ocasionando menor tempo de operação à planta, foram selecionados dois equipamentos para a realização da análise da confiabilidade - a esteira metálica e o guincho Hillo.

Na Tabela 1, estão apresentados os tempos até a falha da esteira metálica e do guincho Hillo, para as duas safras em estudo.

Tabela 1 - Tempos até as falhas para dois equipamentos da planta, para duas safras

\begin{tabular}{|c|c|c|}
\hline & Safra & Tempo até falha (horas) \\
\hline \multirow{4}{*}{$\begin{array}{c}\text { Esteira } \\
\text { Metálica }\end{array}$} & 2017 & $\begin{array}{llllllll}602,83 & 1129,42 & 1272,00 & 2025,67 & 2072,92 & 2401,25 & 2647,00 & 2835,88\end{array}$ \\
\hline & 2011 & 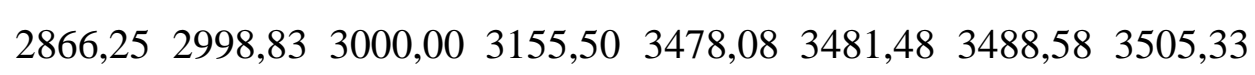 \\
\hline & $/ 2018$ & $\begin{array}{llllll}3620,47 & 3770,20 & 3870,73 & 3879,00 & 4086,50 & 4201,75\end{array}$ \\
\hline & $\begin{array}{r}2018 \\
/ 2019\end{array}$ & $3787,00 \quad 3799,60 \quad 4012,83 \quad 4064,25$ \\
\hline \multirow{2}{*}{$\begin{array}{c}\text { Guincho } \\
\text { Hillo }\end{array}$} & $\begin{array}{c}2017 \\
/ 2018\end{array}$ & $\begin{array}{lllllll}990,33 & 2117,93 & 2271,25 & 2449,50 & 2454,95 & 2490,00 & 2679,17\end{array}$ \\
\hline & $\begin{array}{r}2018 \\
/ 2019\end{array}$ & $\begin{array}{llllllll}1331,42 & 2257,58 & 2924,67 & 3201,80 & 3324,42 & 3407,80 & 3612,37 & 3718,20\end{array}$ \\
\hline
\end{tabular}

Fonte: Elaborado pelo autor e autorizado pela empresa

Os dados disponibilizados foram analisados utilizando o software ProConf (FRITSCH; RIBEIRO, 1998) e avaliados por modelagem com as distribuições de probabilidade Exponencial, Gama, Lognormal e Weibull. O enfoque maior foi dado à distribuição Weibull por ser um dos mais importantes modelos empregados para a modelagem de confiabilidade, devido à sua flexibilidade mediante amostras de tempos de falha com comportamentos distintos. Além disso, explica o comportamento de sistemas onde há a competição entre diversos modos de falha, como equipamentos industriais de considerável complexidade (SELLITTO, 2005; FOGLIATTO; RIBEIRO, 2009). O método gráfico foi utilizado para comparar as curvas da distribuição e verificar qual modelo apresentava melhor aderência aos dados amostrais. 
Para a caracterização da distribuição de frequência, foram aplicados os seguintes testes de aderência às distribuições de probabilidades: Qui-Quadrado $\left(\chi^{2}\right)$ e Kolmogorov-Smirnov (K-S). O software informa o valor p e aponta quais distribuições não podem ser rejeitadas, sendo que a validação é dada se o valor p for maior que 5\% em ambos os testes de aderência.

Em seguida, são fornecidas as estimativas dos parâmetros da distribuição da função distribuição de probabilidade que melhor modela o conjunto de dados em estudo, utilizando o método de máxima verossimilhança. Além disso, são apresentadas as representações das funções de confiabilidade $R(t)$ e de risco ou taxa de falha $h(t)$.

\section{RESULTADOS E DISCUSSÕES}

Os tempos até a falha da esteira metálica e do guincho Hillo foram modelados no ProConf, e a distribuição Weibull foi escolhida para modelar os dados de falhas dos equipamentos em estudo. Um dos motivos é o fato de ser indicada para modelagem de equipamentos industriais onde há possíveis modos de falhas que podem causar a indisponibilidade do ativo (SELLITO, 2005).

\subsection{Análise de falhas da esteira metálica}

Na Figura 4, são apresentados os gráficos dos papéis de probabilidade relativos às safras 2017/2018 e 2018/2019 para os tempos de falha da esteira metálica, para a distribuição Weibull.
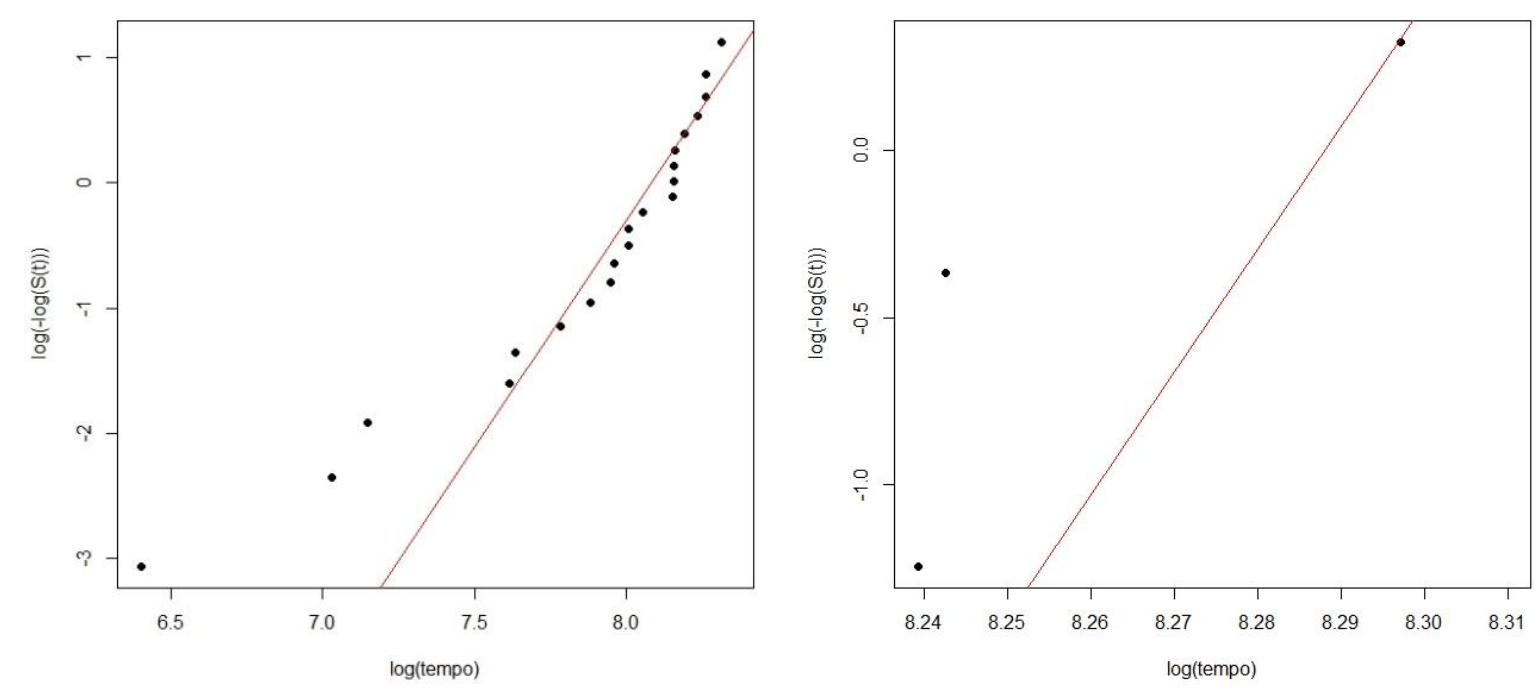

Figura 4 - Papel de probabilidade Weibull para a esteira metálica, safras 2017/2018 e 2018/2019 Fonte: Adaptado do software ProConf. 
As análises dos papéis de probabilidade, mostradas na Figura 4, evidenciam desvios dos pontos em relação à reta, não podendo indicar, com precisão, que o modelo Weibull se ajusta ao conjunto amostral, o que pode ser explicado por ser uma amostra de pequeno tamanho. Assim, os testes de aderência são realizados para validar ou não a modelagem.

Os valores p dos testes de aderência de Qui-Quadrado $\left(\chi^{2}\right)$ e de Kolmogorov-Smirnov (K-S) são apresentadas na Tabela 2. Verifica-se que o valor p é maior que o nível nominal de $5 \%$, para ambas as safras. Esses resultados indicam que a distribuição Weibull não pode ser rejeitada, sendo apropriada para modelar o conjunto de dados amostrais.

Tabela 2 - Valores p dos testes de aderência da Weibull para os tempos de falha da esteira metálica, safras 2017/2018 e 2018/2019

\begin{tabular}{cccc}
\hline Modelo Weibull & $\chi^{2}$ & K-S & Decisão \\
\hline Safra 2017/2018 & 0,0786 & 0,0626 & Não pode ser rejeitada \\
Safra 2018/2019 & 0,1514 & 0,2426 & Não pode ser rejeitada \\
\hline
\end{tabular}

Fonte: Adaptado do software ProConf.

Na Tabela 3, são apresentados os parâmetros da distribuição Weibull, ajustados para os tempos de falha da esteira metálica nas safras 2017/2018 e 2018/2019. A partir do parâmetro de forma, é possível avaliar o estágio de vida do equipamento.

Tabela 3 - Resultados dos ajustes da Weibull para os tempos de falha da esteira metálica, safras 2017/2018 e 2018/2019

\begin{tabular}{ccc}
\hline Parâmetro & Safra 2017/2018 & Safra 2018/2019 \\
\hline$\gamma$ & 3,62 & 36,86 \\
$\theta$ & 3243,73 & 3976,13 \\
\hline
\end{tabular}

Fonte: Adaptado do software ProConf.

Os gráficos das funções confiabilidade referentes às safras 2017/2018 e 2018/2019 estão representados na Figura 5. 

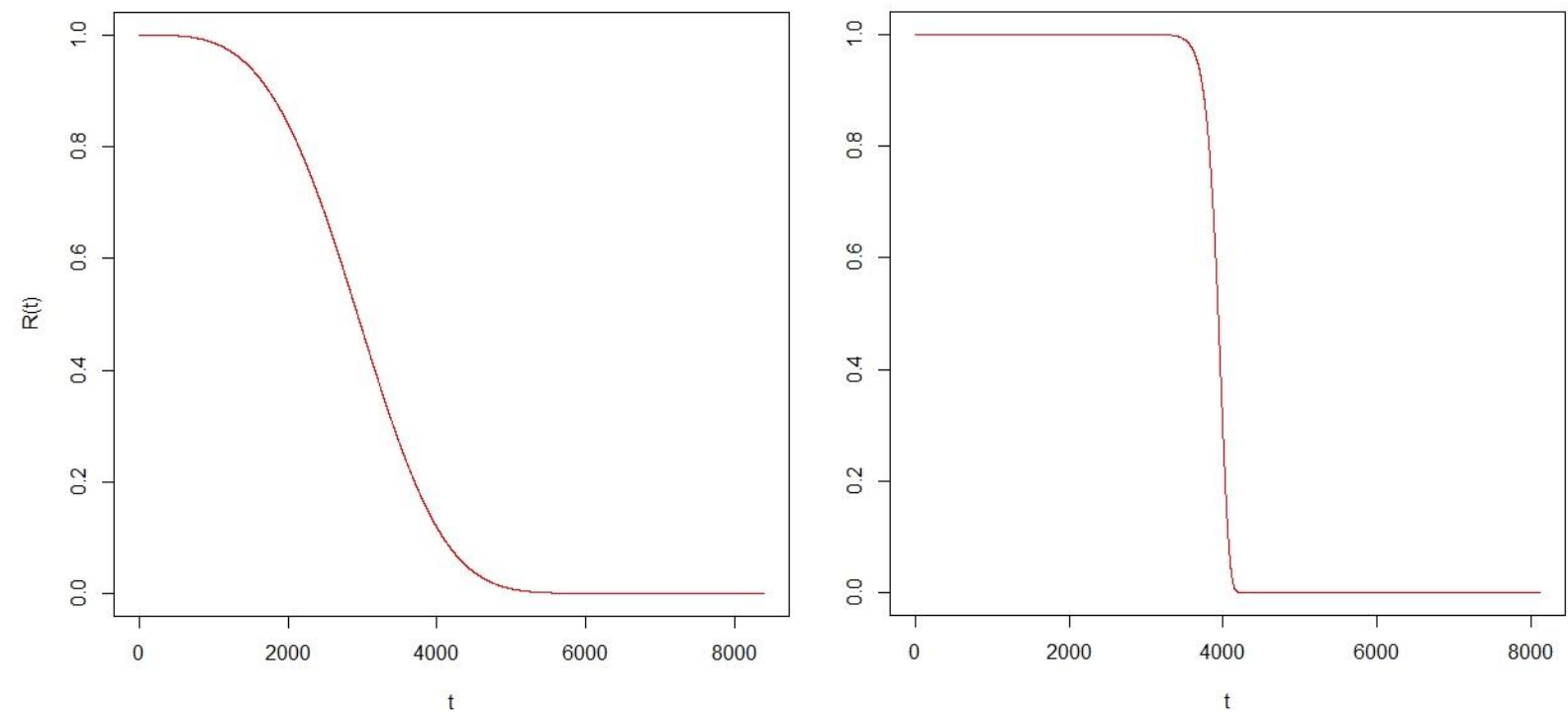

Figura 51 - Funções de Confiabilidade $R(t)$ para a esteira metálica, safras 2017/2018 e 2018/2019

Fonte: Adaptado do software ProConf.

Constata-se que a confiabilidade sempre se dá em uma curva decrescente, em função do tempo, já que as probabilidades de perfeitas condições decaem conforme a utilização e o desgaste do equipamento. A confiabilidade do item foi praticamente constante durante todo o tempo de operação na safra 2018/2019, apresentando queda nos tempos finais.

Os gráficos das taxas de falha ou de risco relativos às safras 2017/2018 e 2018/2019 estão representados na Figura 6.
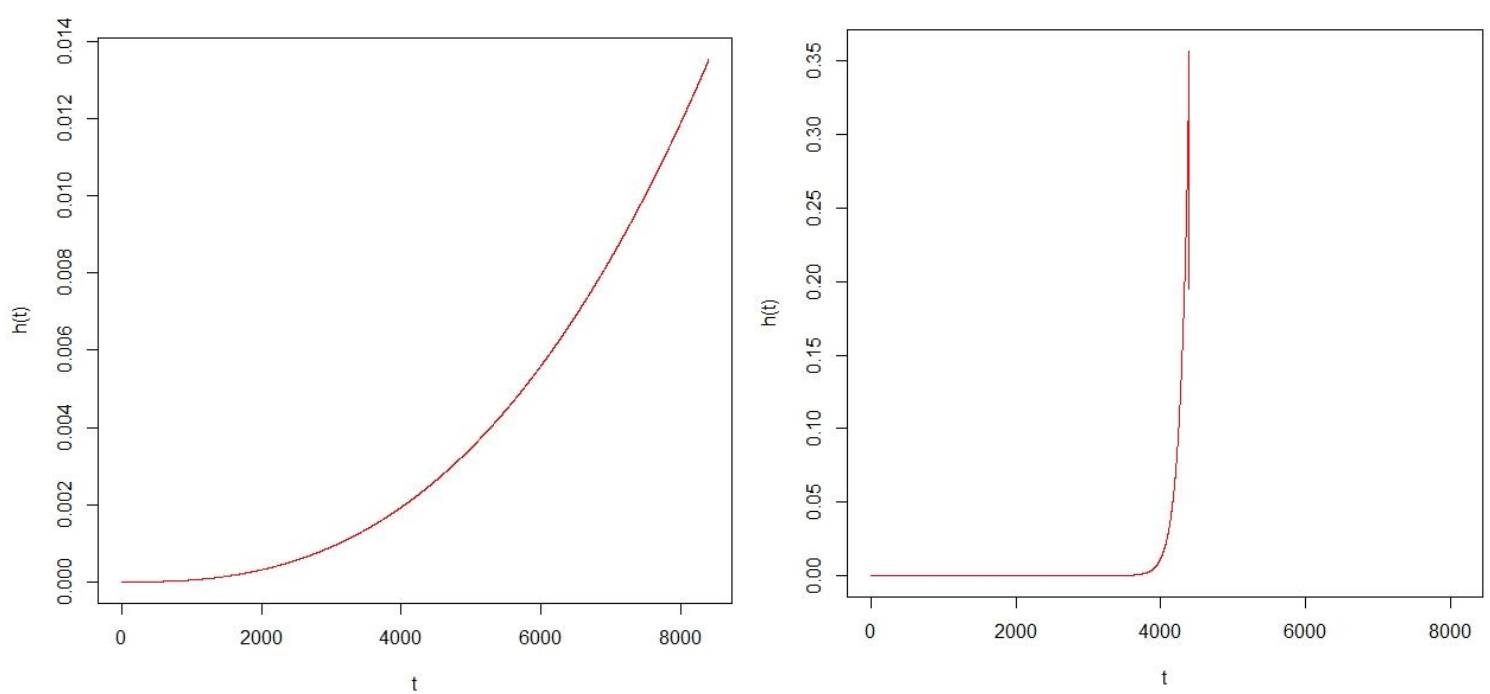

Figura 6 - Taxa de falhas $h(t)$ para a esteira metálica, safras 2017/2018 e 2018/2019

Fonte: Adaptado do software ProConf. 
A esteira metálica apresentou muitas falhas durante a safra 2017/2018, as quais ocorreram distribuídas durante todo o tempo de operação, porém apresentando maior taxa de ocorrência no período final da safra. O parâmetro de forma com valor de 3,62 (Tabela 3) evidenciou, pelo gráfico de taxa de falhas, um crescimento exponencial a partir de 600 horas do início da operação de moagem, que foi se agravando com o decorrer do tempo. Este fato pode ser atribuído ao tipo de reparo que o equipamento sofreu durante a entressafra que precedeu a operação, onde o ativo recebeu o serviço de recondicionamento dos componentes, ao invés da troca por novos.

Durante a safra 2018/2019, foi possível notar que a quantidade de falhas caiu expressivamente em relação à safra anterior. O parâmetro de forma com valor alto de 36,86 (Tabela 3) condiz com a ocorrência de múltiplas falhas em pequeno espaço de tempo, expressando, assim, o período de desgaste acentuado que foi evidenciado apenas no fim da operação de safra, como já era esperado. Durante a entressafra 2018/2019, o equipamento não sofreu apenas os reparos necessários, mas também a troca da maioria dos componentes desgastados, o que justifica sua maior vida útil, de modo geral.

Devido aos valores dos parâmetros de forma para os dois períodos de safra, a manutenção preventiva do equipamento é mais indicada, visto que as falhas tendem a acontecer após certo período de funcionamento. Outro fator de grande importância a ser lembrado é que as solicitações quanto ao funcionamento do equipamento podem variar entre estas safras, causando algum impacto também na ocorrência das falhas.

\subsection{Análise de falhas do guincho Hillo}

Na Figura 7, são apresentados os gráficos dos papéis de probabilidade referentes às safras 2017/2018 e 2018/2019 para os tempos de falha do guincho Hillo, para distribuição Weibull. 

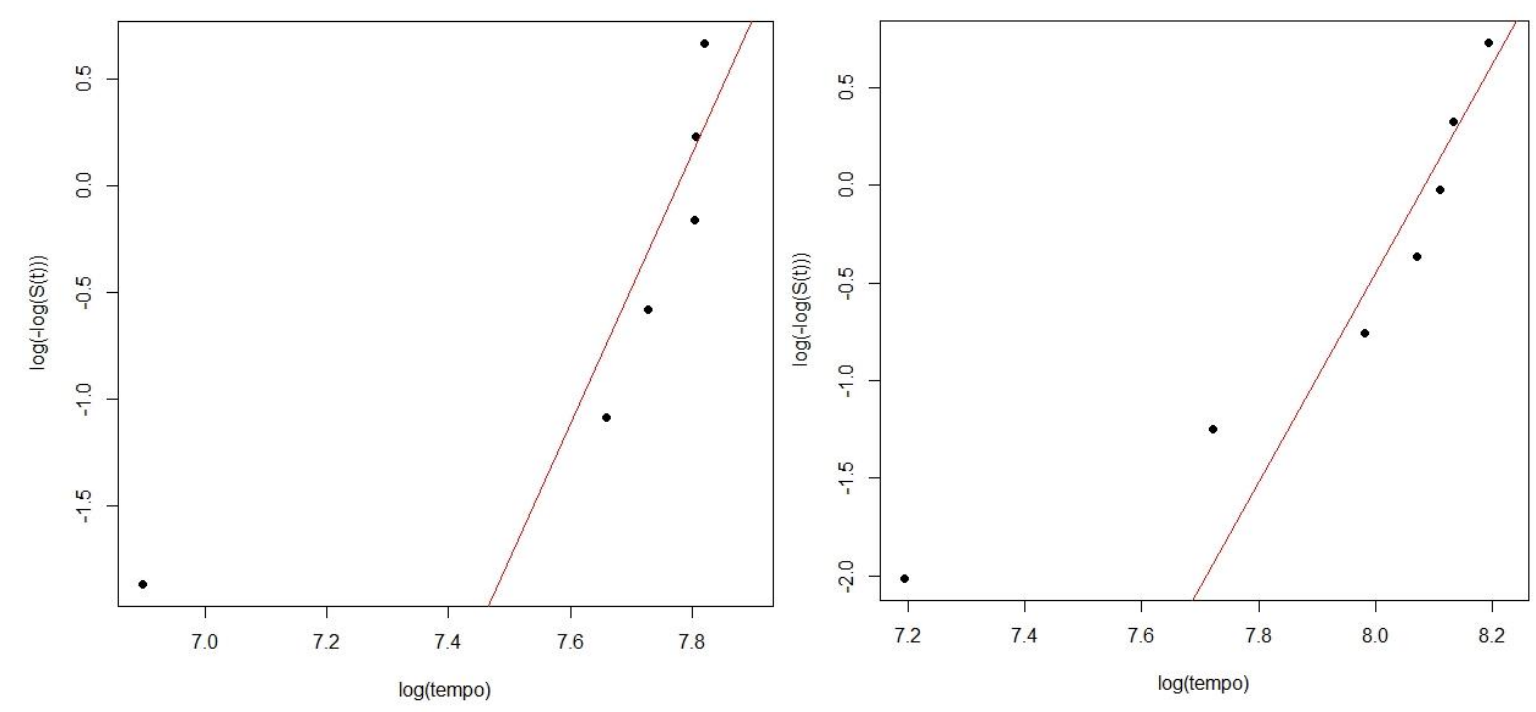

Figura 7 - Papel de probabilidade da Weibull para o guincho Hillo, safras 2017/2018 e 2018/2019 Fonte: Adaptado do software ProConf.

As análises dos papéis de probabilidade, exibidas na Figura 7, mostram que há desvios dos pontos em relação à reta, não podendo indicar se o modelo Weibull se ajusta ao conjunto amostral. Assim, os testes de aderência são realizados para validar ou não a modelagem pela distribuição Weibull.

Os valores $\mathrm{p}$ dos testes de aderência Qui-Quadrado $\left(\chi^{2}\right)$ e de Kolmogorov-Smirnov (KS) são apresentadas na Tabela 4. Da mesma forma que para a esteira metálica, observa-se que o valor p é maior que o nível nominal de 5\%, para ambas as safras. Esses resultados indicam que a distribuição Weibull não pode ser rejeitada, sendo apropriada para modelar o conjunto de dados amostrais.

Tabela 4 - Valores p dos testes de aderência da Weibull para os tempos de falha do guincho Hillo, safras 2017/2018 e 2018/2019

\begin{tabular}{cccc}
\hline Modelo Weibull & $\chi^{2}$ & K-S & Decisão \\
\hline Safra 2017/2018 & 0,1187 & 0,0643 & Não pode ser rejeitada \\
Safra 2018/2019 & 0,1055 & 0,1360 & Não pode ser rejeitada \\
\hline
\end{tabular}

Fonte: Adaptado do software ProConf.

Na Tabela 5, são apresentados os parâmetros da distribuição Weibull, ajustados para os tempos de falha do guincho Hillo nas safras 2017/2018 e 2018/2019. 
Tabela 5 - Resultados dos ajustes da Weibull para os tempos de falha do guincho Hillo, safras 2017/2018 e 2018/2019

\begin{tabular}{ccc}
\hline Parâmetro & Safra 2017/2018 & Safra 2018/2019 \\
\hline$\gamma$ & 6,35 & 5,37 \\
$\theta$ & 2385,02 & 3241,02 \\
\hline
\end{tabular}

Fonte: Adaptado do software ProConf.

Os gráficos das funções confiabilidade, para o guincho Hillo, referentes às safras 2017/2018 e 2018/2019, estão representados na Figura 8.
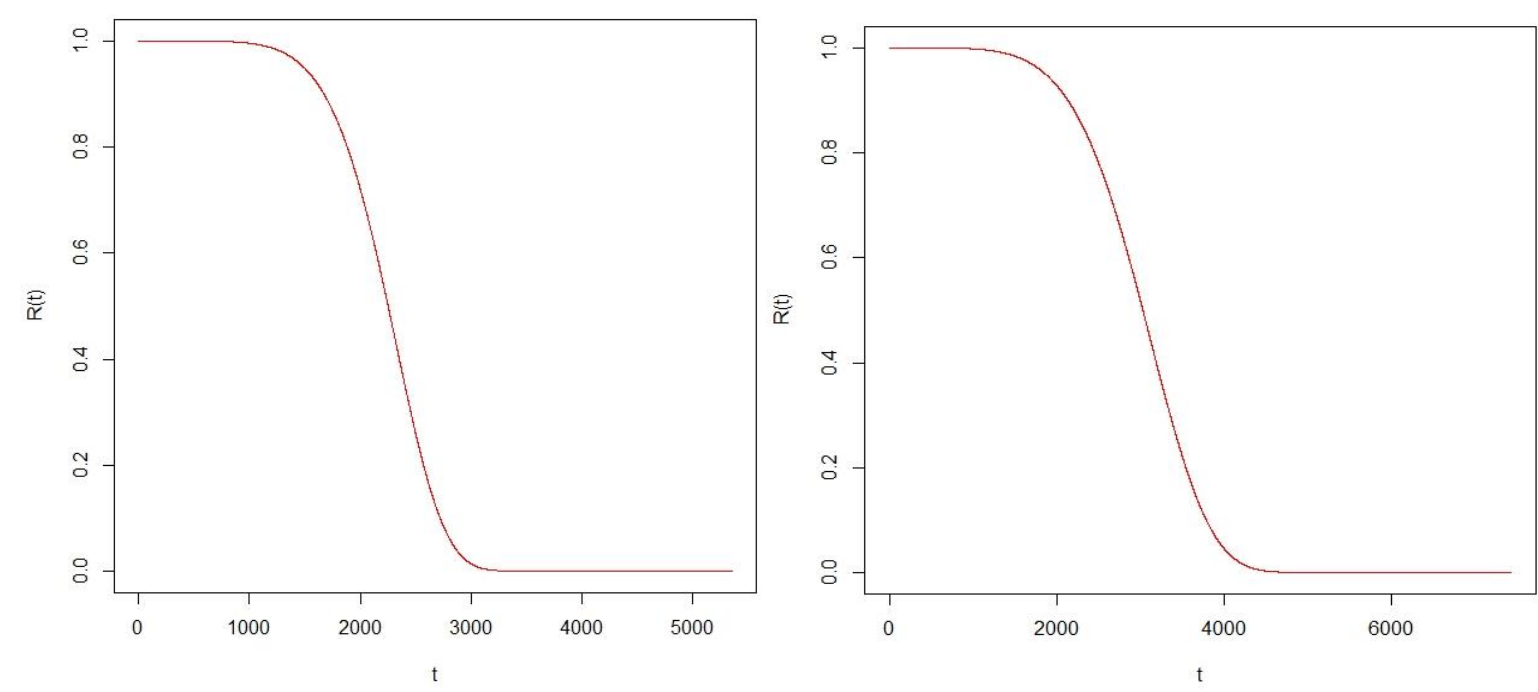

Figura 8 - Funções de Confiabilidade $R(t)$ para o guincho Hillo, safras 2017/2018 e 2018/2019 Fonte: Adaptado do software ProConf.

Constata-se que as funções de confiabilidade foram similares nas duas safras. Durante a safra 2017/2018, é notório que o decrescimento da confiabilidade ocorreu de modo mais agudo, enquanto na safra 2018/2019, ele se mostrou mais brando.

Os gráficos das funções de falha, para o guincho Hillo, referentes às safras 2017/2018 e 2018/2019, estão representados na Figura 9. 

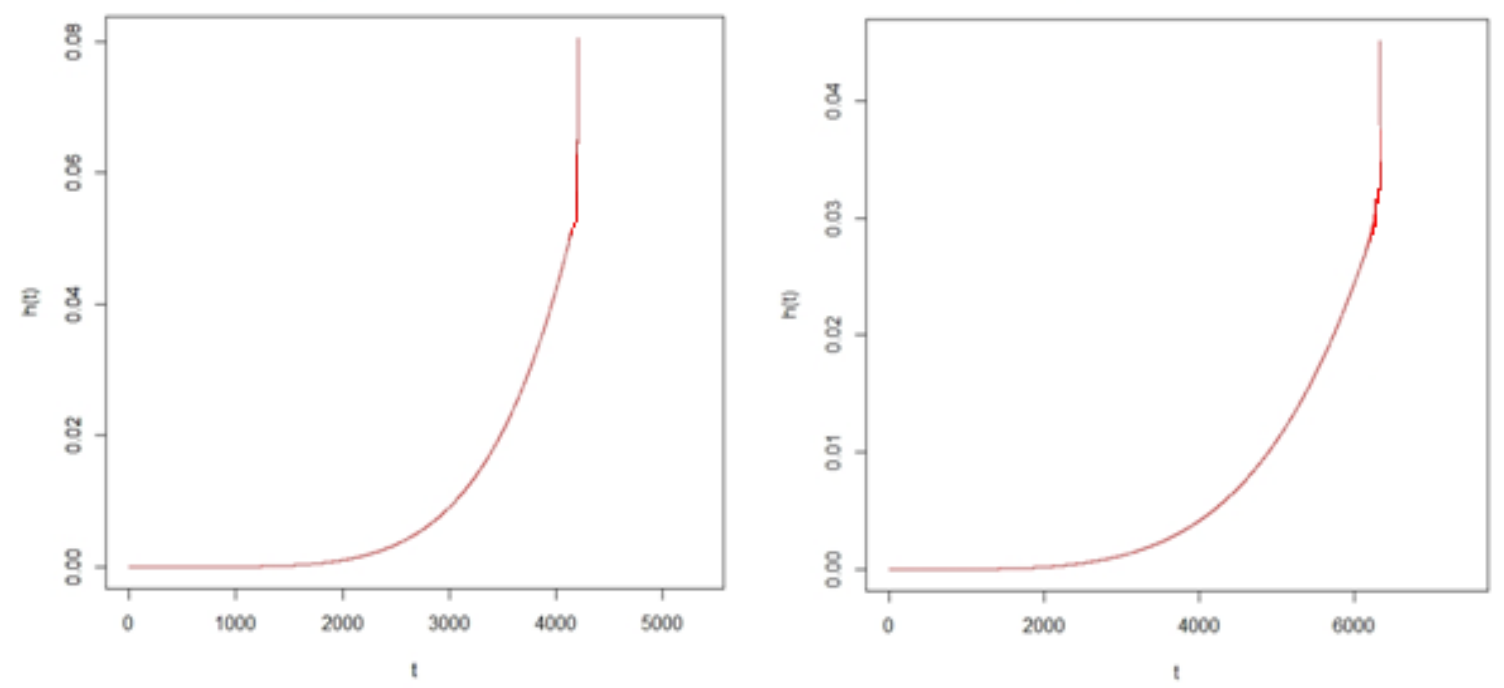

Figura 9 - Taxa de falhas h(t) para o guincho Hillo, safras 2017/2018 e 2018/2019 Fonte: Adaptado do software ProConf.

A taxa de falhas do equipamento se manteve próxima, comparando-se os dois períodos. Isto pode ser justificado pelo fato de os parâmetros de forma nas duas safras apresentar valores próximos, 6,35 e 5,37 (Tabela 5), respectivamente, para as safras 2017/2018 e 2018/2019, indicando que o melhor tipo de manutenção a ser aplicada é a preventiva.

Além das análises computacionais, foi realizado um estudo das falhas que comumente ocorrem no guincho Hillo. A maior incidência de falhas acontece em relação ao movimento entre os cabos do guincho e as roldanas do balanção - peça de encaixe para despejo da cana na mesa alimentadora.

Mediante tal ocorrência, foi executado um brainstorming, levantando hipóteses do que pode estar causando essa falha sistemática. Tais hipóteses foram avaliadas por meio de um diagrama de Ishikawa, disposto na Figura 10.

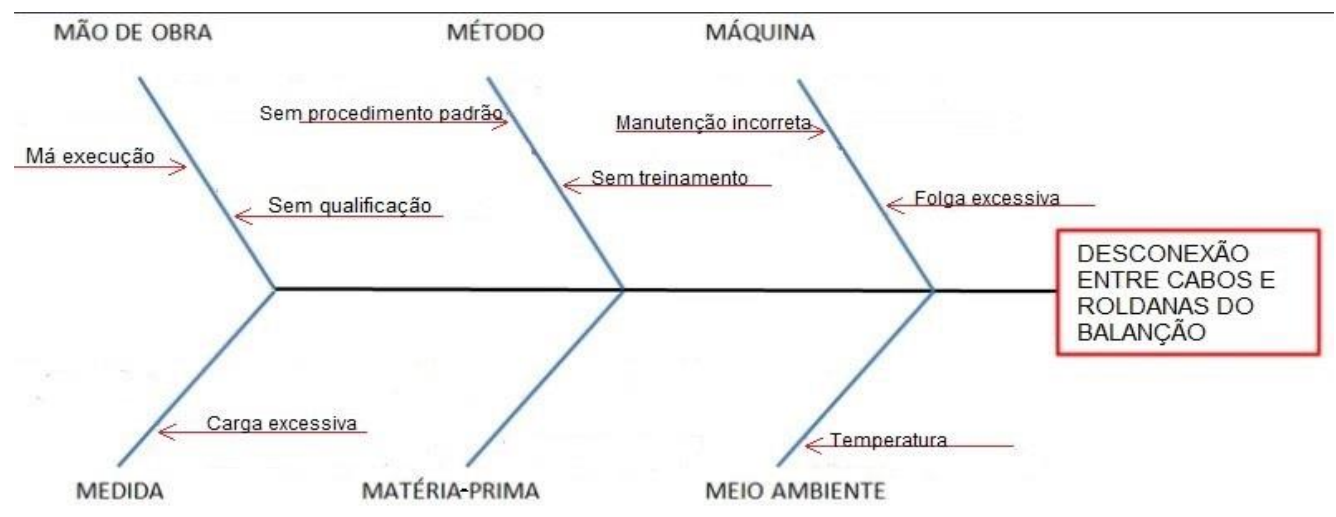

Figura 10 - Diagrama de Ishikawa Guincho Hillo Fonte: Elaborado pelo Autor. 
Avaliando as possíveis hipóteses, foi possível chegar à causa da falha: folga excessiva entre os elementos rolantes que compõem o sistema do balanção. Logo, foram realizados estudos e verificações na área da usina, analisando esta causa. Assim, foi projetada uma peça para ser usada como um guia para o cabo, denominada Anel-Guia, com a finalidade de evitar que, mesmo diante de choques ou alterações de cargas imprevistas, o cabo não perca o contato com a pista interna da roldana.

Utilizando um software CAD, realizou-se um desenho 3D do Anel-Guia (Figura 11), de modo a avaliar a sua aplicação e funcionalidade mediante a simulação no software.

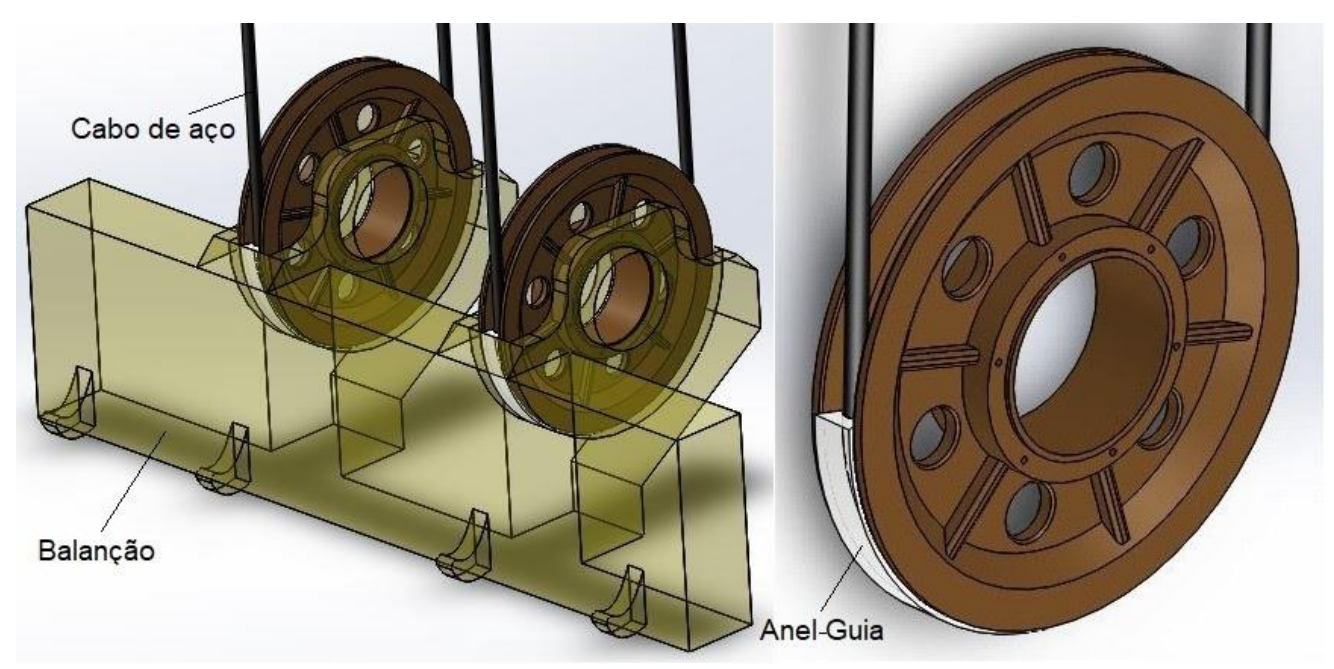

Figura 11 - Desenho 3D Anel-Guia

Fonte: Elaborado pelo autor.

A execução desta etapa de análise, projeto e aplicação, junto à manutenção, gera resultados significantes para a planta fabril. Em média, são gastas seis horas de manutenção corretiva durante as safras para corrigir o escape do cabo de aço e liberar o equipamento para a operação. Logo, a aplicabilidade do Anel-Guia projetado gera maior tempo de operação ao equipamento, bem como possibilita maior tempo disponível aos técnicos de manutenção, uma vez que não terão que atuar neste ativo devido a essas falhas sistemáticas.

\section{CONCLUSÕES}

É crucial ressaltar a importância de conhecer bem os ativos, assim como os modelos de manutenção aplicáveis de acordo com a planta operação disposta na empresa. Os gestores de manutenção e os técnicos que irão aplicar as ferramentas de manutenção para o 
planejamento devem ser qualificados e capacitados. Compreender as falhas ocorrentes, bem como os dados de falhas, interpretando-os e analisando-os por meio de softwares computacionais, é de extrema relevância. Com os estudos e análises realizados, foi possível obter mais informações a respeito da ocorrência das falhas e identificar possíveis erros de manutenção, operação ou desgaste dos ativos.

O uso destes métodos estatísticos e analíticos e sua aplicação junto ao planejamento de manutenção são capazes de gerar aumento da eficiência operacional e logística da empresa, auxiliando na redução de gastos, minimizando o tempo para reparos e maior disponibilidade dos equipamentos. Este tipo de estudo pode ser implementado automaticamente junto ao sistema de gestão de manutenção ao inserir as informações relativas às falhas.

A utilização dos métodos analíticos aplicados se mostra de fácil execução para usinas sucroalcooleiras, como a usina estudada. O uso de ferramentas da manutenção também é um ponto importante de ser aplicado pelo PCM. A análise desenvolvida foi essencial para gerar um feedback sobre as falhas do guincho Hillo, sendo possível gerar uma solução e aplicá-la na prática, em meio à operação.

Para futuros estudos, pode-se realizar o estudo de confiabilidade para outros tipos de equipamentos que compõem uma usina sucroalcooleira, desde válvulas e atuadores até equipamentos de maior porte, como uma caldeira, por exemplo.

\title{
ANALYSIS OF EQUIPMENT FAILURES AND THE IMPORTANCE OF MAINTENANCE PLANNING: AN APPLICATION IN A SUGAR AND ALCOHOL PLANT
}

\begin{abstract}
Through technological advances, the globalization of the market and the demand for production at lower costs, today's organizations aim for greater productivity, requiring equipment with high reliability and availability. The need arises to maximize the time in operation of the industrial plant in order to guarantee greater production. The objective of this work was to perform a failure analysis of equipment used in the sugarcane milling sector of a sugar and ethanol mill. The applied research method consisted of the case study. For the analysis, the collection of times until equipment failure, and, for modeling of the data, the software ProConf was used. The modeling of the reliability and failure rate of the equipment was done in order to identify the phase of their life. The distribution that best fits the times is Weibull. It was possible to generate the reliability and failure rate graphs, identifying that the equipment are in the senile life stage, and preventive maintenance is more indicated. It was found that excessive play between the rolling elements that make up the swinging system was the main cause of failure in the Hillo winch, and a guide ring was designed for the cable in order to avoid further problems.
\end{abstract}

Keywords: Reliability. Life phase. Preventive maintenance. Modeling. Weibull. 


\section{EFERÊNCIAS}

ASSOCIAÇÃO BRASILEIRA DE MANUTENÇÃO E GESTÃO DE ATIVOS ABRAMAN. A situação da manutenção no Brasil. Bahia, set. 2013.

ASSOCIAÇÃO BRASILEIRA DE NORMAS TÉCNICAS. NBR 5462: Confiabilidade e Mantenabilidade. Rio de Janeiro: ABNT, 1994.

BRANDÃO, Mariane Olivier; ANDRADE, Paulo César de Resende. Modelagem dos dados de falhas de um pasteurizador de garrafas de cerveja. Revista de Engenharia e Tecnologia, Ponta Grossa, v. 10, n. 2, p. 172-181, 2018.

CARDOSO, Idelcio Alexandre P; PERES, Mayara Lima; NETO, Francisco de Castro M. A importância da manutenção para o negócio. In: ENCONTRO NACIONAL DE ENGENHAIRA DE PRODUÇÃO, 31, Belo Horizonte, 2001. Anais [...] Belo Horizonte, 2001.

CIRINO, Tânia Maria Astun; PASCHOALATO, Cristina Filomena Pereira Rosa; KRONKA, Eloísa Aparecida M.; MELLIS, Graziela Vicari. Planejamento e diretrizes para um sistema de gestão ambiental em uma indústria sucroalcooleira. p. 1-10. Disponível em http://www.do.ufgd.edu.br/gersonhomem/images/TAA/texto2.pdf. Acesso em: 05 nov. 2018.

COMPANHIA NACIONAL DE ABASTECIMENTO - CONAB. Acompanhamento da safra brasileira de cana-de-açúcar. Brasília, p 1-86, 2018.

FOGLIATTO, Flávio Sanson; RIBEIRO, José Luís Duarte. Confiabilidade e manutenção industrial. Rio de Janeiro: Elsevier, 2009.

FRITSCH, Celso; RIBEIRO, José Luis Duarte. PROCONF: um software orientado para análises de confiabilidade. In: ENCONTRO NACIONAL DE ENGENHARIA DE PRODUÇÃO, 18, Niterói, 1998. Anais [...] Niterói, 1998.

FUENTES, Fernando Félix Espinosa. Metodologia para inovação da gestão de manutenção industrial. 2006. 208 f. Tese (Doutorado em Engenharia Mecânica) Universidade Federal de Santa Catarina, Florianópolis, 2006.

KARDEC, Alan; NASCIF, Júlio. Manutenção: função estratégica. 3 ed. Rio de Janeiro: Qualitymark, 2009.

LEAL, Manoel Regis Lima. Tecnological evolution of sugarcane processing for ethanol and electric power generation. p.461-576. In: Sugarcane bioethanol - R\&D for Productivity and Sustainability, São Paulo: Blucher, 2014. Disponível em:

https://openaccess.blucher.com.br/article-details/19270\%20. Acesso em: 15 nov. 2018.

LEAL, Vítor Justus; ANDRADE, Paulo César de Resende. Modelagem dos dados de falha de um caminhão fora de estrada. ForScience: revista científica do IFMG, Formiga, v. 6, n. 3, 2018.

MOUBRAY, John. Manutenção centrada na confiabilidade. São Paulo: Aladon Ltda, 1997. $212 \mathrm{p}$. 
SANTOS, Maicon Mateus de Medeiros; SILVA, Evaldo da Conceição; FERREIRA, Gabriel de; SILVA, Renan Martinielli Gonçalves; ANDRADE, Paulo César de Rezende. Modelagem do tempo de vida de um inversor de frequência. ForScience: revista científica do IFMG, Formiga, v. 5, n. 3, 2017.

SELLITTO, Miguel Afonso. Formulação estratégica da manutenção industrial com base na confiabilidade dos equipamentos. Revista Produção, Piracicaba, v. 15, n. 1, p. 44-59, 2005.

SILVA, Evaldo da Conceição; FERREIRA, G. de S.; SANTOS, M. M. de M.; ANDRADE, P. C. de R.; ROSA, R. M. G. Análise de Dados de Falha de um Transmissor de Fibra Óptica. Revista Thema, Pelotas, v. 14, n. 4, p. 259-266, 2017.

SILVA, Ellen Maria Neves; ANDRADE, Paulo César de Resende. Análise de confiabilidade de um inspetor eletrônico de garrafas. Revista da Universidade Vale do Rio Verde, Betim, v. 16, n.2, p. 1-9, 2018.

SOUZA, José Barrozo de. Alinhamento das estratégias do planejamento e controle da manutenção (PCM) com as finalidades e funções do Planejamento e controle da produção (PCP): uma abordagem analítica. Dissertação (Mestrado em Engenharia de Produção) - Universidade Tecnológica Federal do Paraná, Ponta Grossa, 2008.

VIANA, Hebert Ricardo Garcia. PCM, planejamento e controle de manutenção. Rio de Janeiro: Qualitymark, 2002.

WAEYENBERGH, Geert; PINTELON, Liliane. A framework for maintenance concept development. p. 299-313. In: Int. J. Production Economics 77, 2002. p. 299-300.

https://pdfs.semanticscholar.org/896c/9b58c3bc7d2025c7d83dfc1cd92f95a3e60b.pdf. Acesso em: 01 dez. 2018.

\section{DADOS DOS AUTORES}

Felipe Campos Silva Barbosa

E-mail: felipecsbarbosa@gmail.com

Currículo Lattes: http://lattes.cnpq.br/0441880201314013

Graduado em Ciência e Tecnologia e Engenharia Mecânica pela Universidade Federal dos Vales do Jequitinhonha e Mucuri (UFVJM) Campus JK e pós graduando em Engenharia de Manutenção pelo Instituto de Educação Tecnológica (IETEC). Atualmente é responsável pelo planejamento de manutenções preventivas de colhedoras de cana, máquinas agrícolas, implementos e caminhões, visando seu perfeito funcionamento, prolongamento da vida útil e melhoria contínua. Analista de indicadores de manutenção integrado ao planejamento de manutenções preventivas, corretivas programadas e preditivas.

\section{Paulo César de Resende Andrade}

E-mail: pceandrade@gmail.com ou paulo.andrade@ict.ufvjm.edu.br

Currículo Lattes: http://lattes.cnpq.br/0894646446086485

Possui doutorado e mestrado em Estatística e Experimentação Agropecuária, graduação em Engenharia Industrial Elétrica, graduação e especialização em Matemática pela Universidade Federal de Lavras (UFLA). Atualmente é professor Associado II do Instituto de Ciência e 
Tecnologia da Universidade Federal dos Vales do Jequitinhonha e Mucuri (UFVJM), Campus de Diamantina. Professor do Programa de Pós-Graduação em Educação da UFVJM (Mestrado) e do Programa de Pós-Graduação em Produção Vegetal da UFVJM (Mestrado e Doutorado). 